\title{
"Christ offered salvation, and not an easy life": How do port chaplains make sense of providing welfare for seafarers? An idiographic, phenomenological approach analysis
}

\author{
Tiffany Palmer, Esther Murray
}

London Metropolitan University, United Kingdom

\begin{abstract}
Background: The shipping industry has historically leaned towards a biomedical model of health when assessing, treating and caring for seafarers. In recent years there has been more concern for the mental health of seafarers in both the academic literature and the commercial world, however, the psychological and emotional well-being of seafarers still largely falls on the shoulders of the port chaplains. The aim of the study was to explore how port chaplains make sense of providing welfare for seafarers by taking an idiographic, phenomenological approach (IPA).

Materials and methods: Six male participants working as chaplains in United Kingdom ports took part in recorded face-to-face, semi-structured interviews covering three areas of questioning: role, identity and coping. Interviews were transcribed verbatim, and data analysed using interpretative phenomenological analysis.

Results: Three super-ordinate themes were identified from participants accounts; "We walk a very strange and middle path", "Exploited" and "Patching up". Rich data emerged in relation to the personal impact chaplains felt they made, which was facilitated by the historical role of the Church; this led to the second super-ordinate theme of how chaplains felt towards seafarers. Lastly, the analysis demonstrates how chaplains adapt to the limitations forced upon them to provide welfare, and a degree of acceptance at the injustice.

Conclusions: Results were discussed in reference to theoretical models, including self-efficacy, empathic responding and the transactional model of stress and coping. Chaplains in ports perform their role autonomously with no input from healthcare professionals. Recommendations are made for a biopsychosocial model of health involving primary care, benefiting the health and well-being of seafarers and providing support and guidance for port chaplains at the frontline of welfare for seafarers.
\end{abstract}

(Int Marit Health 2016; 67, 2: 117-124)

Key words: seafarers, health psychology, port chaplains, IPA

\section{INTRODUCTION}

Within the maritime world, chaplains have a long-standing historical involvement providing welfare for people of all cultures and backgrounds. Within the shipping industry, the role of the chaplain has appeared to have changed little throughout history. The risks to seafarers' - ill health, injury and death have been well-documented [1], but it is the chaplains that have provided pastoral care for the spiritual, physical and emotional health of seafarers since the early 1800's [2], which have up to now been neglected in research.

Whilst a move towards a biopsychosocial model of health is emerging, at present it is still the port chaplains 
that are at the forefront of care in relation to psychological and emotional health and well-being [3]. Health psychology has recognised the importance of understanding personal perceptions and it is this idiographic, phenomenological approach (IPA) that has allowed researchers to explore the subjective experience and is concerned with the detailed examination of personal lived experience [4]. The three main components that have developed into the defining characteristics of IPA are a theoretical commitment to phenomenology, hermeneutics and idiography [5].

With its origins in phenomenology, IPA is concerned first and foremost with an individual's experience of phenomena, as described above. Alongside this, IPA acknowledges that we cannot gain direct access to a person's experience and recognises the researcher's role in interpreting and analysis. This is the concept of hermeneutics. In addition, IPA is concerned with a small sample size, enabling the researcher to gain richer more meaningful data of a homogenous group, rather than mass generalisations on large populations (nomothetic), hence the third element, idiography. It is this very personal narrative with careful interpretation that is the key tenet of IPA [6].

This paper examines the chaplain as a neglected and largely invisible actor within the field of industrial relations. The aim of this study is to establish how chaplains make sense of providing welfare for seafarers that are forced to deal with chronic stress and often experience severe trauma. Chaplains have been described as low-profile counsellors [7], and the role they perform is further convoluted by practical and political constraints preventing any meaningful and effective intervention by a chaplain, to alleviate the problems experienced by seafarers or even escalate concerns up the chain of command. Interpretative phenomenological analysis was adopted because its focus addresses a hermeneutic of empathy, and explores the relationship between what people say, and the way they think about their own experiences, as well as "advocating that the body, the mind and the social world interact" (Pg. 462) [8]. IPA's concern with idiographic accounts and rich data, provide an opportunity for research to examine how port chaplains make sense of providing welfare for seafarers, and this previously neglected group is the focus of this study.

\section{MATERIALS AND METHODS}

\section{PARTICIPANTS}

Using criterion sampling, this research explores how port chaplains make sense of providing welfare to seafarers. Hence, participants were selected based on having experience of the phenomena and working as full-time chaplains at United Kingdom ports. Six chaplains agreed to be interviewed. All 6 chaplains were based at the seafarers' centres at various ports around the United Kingdom. Chaplains share the seafarers' centre regardless of Christian denomination and there is strong support for an ecumenical approach to working. The names of participants have been changed to protect identity.

\section{MATERIALS}

An interview was devised with a semi-structured framework. Consistent with IPA, it was non-directive using open-ended questions, therefore enabling the participant to tell their story in their own words. It was aimed at gaining participant's sense making of providing welfare to seafarers. Interview questions were focusing on three main areas of interest (Table 1).

\section{METHODS}

IPA is not a prescriptive approach, but rather a set of guidelines [9]. For the purpose of this research, narratives were analysed using the practice set out in Smith [10]. According to Smith, a theme must be "recurrent", that appears in at least $50 \%$ of the transcripts.

Key words were employed to capture the essence of participants' experience. Adopting an emic versus etic approach, alternating between the researcher's analysis and the text, is imperative in ensuring the researcher stays close to the text, by checking that themes are accurate and are actually present in the transcripts [11]. This cyclical process required returning to the data several times, as themes changed in name, were altered or added. Themes were then listed in chronological order and examined. Attempts were made to establish links or relationships between them and to group them together. As themes were arranged into clusters, overarching "superordinate" themes were established, informed by psychological knowledge and theory. The themes that are not significant for at least $50 \%$ of the participants are omitted. As a result of this cyclical process, the final themes that emerged are relevant to all participants in this study.

\section{RESULTS}

This section highlights three inter-related superordinate themes that emerged from the participants' transcripts: "We walk a very strange and middle path", "Exploited" and "Patching up", and sub-themes within them (Table 2).

\section{1."WE WALK A VERY STRANGE AND MIDDLE PATH"}

Overall the participants reported their role as being twofold. Firstly, the role performed by chaplains is unique to the missions that are based at ports, defined by the historical relationship between the maritime world and the Church, and their reputation preceded them. Secondly, with no other 
Table 1. Interview questions and prompts

\author{
Role of chaplains \\ What do you enjoy about your job? \\ Prompt: Why? \\ What it the hardest part of your job? \\ Prompt: Tell me about that. \\ What are the most common issues you deal with? \\ Prompt: Why do you think that is? \\ What do you think are the biggest health challenges for seafarers? \\ What do you think shipping companies could do to alleviate some of the problems for seafarers? \\ Identity \\ Do you see your role as valuable? \\ Prompt: Why? \\ In what ways has the role of the chaplain changed? \\ How do you deal with someone that comes to the seafarers centre in great distress? \\ Do you ever see religion as a barrier for helping seafarers of different faiths? \\ Prompt: How do you overcome that? \\ Coping \\ Do you feel you have enough qualifications and training to deal with some of the harder issues? \\ Prompt: Tell me about that. \\ So as a chaplain, where do you get your support from? \\ So if you have someone come into port either in physical or emotional distress, how do you deal with that? \\ Do you have other people you can call on or refer to in a crisis, like other healthcare professionals? \\ Prompt: How does that process work?
}

Table 2. Summary table of super-ordinate themes and sub themes and sample quotations

\begin{tabular}{|c|c|c|c|}
\hline Super-ordinate Theme & Sub-themes & Participant / Line & Quotation \\
\hline \multirow[t]{4}{*}{$\begin{array}{l}\text { "We walk a very strange } \\
\text { and middle path" }\end{array}$} & \multirow[t]{2}{*}{ "A ministry of presence" } & John / L120-122 & $\begin{array}{l}\text { You don't have to think, "Well, he's coming from a diffe- } \\
\text { rent religion to preach", he's not going to do that. }\end{array}$ \\
\hline & & Peter / L635-639 & $\begin{array}{l}\text { Whatever chaplains groups there are, there is somebo- } \\
\text { dy there, it they come on, they know they are the type of } \\
\text { people to share their problem with and I think they do } \\
\text { trust us and who we are. }\end{array}$ \\
\hline & \multirow[t]{2}{*}{$\begin{array}{l}\text { "Your presence can be } \\
\text { meaning for somebody" }\end{array}$} & Mark / L78-80 & $\begin{array}{l}\text { The joy, the presence there to listen, to support somebo- } \\
\text { dy and tell something and they accept it, they believe it } \\
\text { and it is amazing. }\end{array}$ \\
\hline & & $\begin{array}{l}\text { William / L61-62... } \\
\text {...66-67 }\end{array}$ & $\begin{array}{l}\text { They want to talk to someone, to a real person... you are } \\
\text { bringing this human face to this hostile world of enormo- } \\
\text { us size of concrete and steel industry. }\end{array}$ \\
\hline \multirow[t]{4}{*}{ "Exploited" } & \multirow[t]{2}{*}{ “Treating him like dirt' } & John / L136-137 & $\begin{array}{l}\text { I think they (seafarers)... like they have to be strong for } \\
\text { their families and so it doesn't matter how they feel. }\end{array}$ \\
\hline & & Peter / L126-127 & $\begin{array}{l}\text { That's the asset [person] that is actually bringing your } \\
\text { life blood and you are treating him like dirt. }\end{array}$ \\
\hline & \multirow[t]{2}{*}{ I do not blame anybody" } & Matthew / L122-123 & $\begin{array}{l}\text { Sometimes they just want to express their upset and } \\
\text { say "Look, I'm hurting", and you say "Yes, I know". }\end{array}$ \\
\hline & & Mark / L347-349 & $\begin{array}{l}\text { I do not blame anybody who doesn't want to go out } \\
\text { because they want to rest, you have to look at yourself } \\
\text { because this is a very hard job. }\end{array}$ \\
\hline \multirow[t]{4}{*}{ "Patching up" } & \multirow[t]{2}{*}{ "I am only a guest" } & Mark / L447-450 & $\begin{array}{l}\text { Yes you help them, but only very short time... they move } \\
\text { from a to b very fast and work conditions is very hard. }\end{array}$ \\
\hline & & Matthew / L111-113 & $\begin{array}{l}\text { It's about overcoming and creating a situation where } \\
\text { they at least come away feeling a bit better in them- } \\
\text { selves... but it's still a challenge. }\end{array}$ \\
\hline & \multirow[t]{2}{*}{$\begin{array}{l}\text { "God offered salvation, } \\
\text { and not an easy life" }\end{array}$} & Peter / L278-280 & $\begin{array}{l}\text { There's nothing you can actually do, I think, but actually } \\
\text { listen to him and I think that's what you do, listen to him. }\end{array}$ \\
\hline & & Mark / L417-418 & $\begin{array}{l}\text { Maybe it's not my thing... I move to another ship and } \\
\text { think maybe I can help this one... I pray. }\end{array}$ \\
\hline
\end{tabular}


healthcare professionals at the forefront of mental health and well-being for seafarers the provision of practical and pastoral care to seafarers is vital.

\section{"A ministry of presence"}

The shape of missions at ports around the world has a long and broad history [12]. Participants report that this role is powerful in its definition, and shapes the expectations and awareness of their presence today. Participants speak with a confidence and self-assurance, and have a strong sense of identity.

Whatever chaplains' groups there are, there is somebody there, if they come on [to the ship], they [seafarers] know they [chaplains] are the type of people to share their problem with, and I think they do trust us and who we are. (Peter)

The consistent use of pronouns "us" and "we" in interview transcripts, perhaps reflects how the chaplains' identity is embedded in the Church, and they feel as if they belong. Despite being of different Christian denominations, chaplains speak with unity and a strong sense of identity. This illustrated a sense of belonging and their role as being well-defined by the Church and its' history. There was a strong convergence amongst chaplains that their role was not to preach. This unique role of the chaplain, to provide pastoral care and welfare along with practical support, without seen to be preaching, is the essence of their role.

\section{"Your presence can be meaning for somebody"}

All participants report "listening" and "being there" as the fundamental purpose of their role. Given the long-standing relationship between the Church and the maritime world, seafarers know who they are, and why they are there, that they are people to be trusted, and anything they discuss will be confidential.

The personal impact provided by chaplains is vital. Seafarers are often on ships with multi-national crew, making it hard to build relationships and friendships on board, with cultural differences and language barriers - making the contact with the chaplain all the more significant. The value of listening, and being the emotional and psychologically support for people working at sea, is not underestimated by the participants. The personal impact that participants believe they make, further affirms their sense of identity and the unique role they play.

Divergence within the accounts of participants was in relation to the Captain, only two participants mentioned the Captain in particular. Peter stated:

Remember... the loneliest place on that ship is the Captain. Who has he got to talk to? Who cares about him?... If you actually lance his world... those little men under him are going to be looked after. Ten minutes with the Captain is a good investment with looking after the crew. (Peter)
This divergence is noteworthy since the two chaplains that mentioned the Captain specifically, were the most knowledgeable and experienced of all participants. This gave new insight into the role of "listening" and "being there", since Peter and Mark, both gave priority to the Captain as they felt this was looking after the crew by default, whereas the remaining (less experienced) chaplains felt those of lower "rank" were the ones that needed the most attention.

\section{2. "EXPLOITED"}

All participants felt a strong sense of injustice for the seafarers. They lay the blame squarely on the shoulders of the shipping companies, however the huge market demand for goods by the West only facilitates the globalised market. Participants' accounts report how seafarers from the developing world have no choice if they are to provide for their families, and this induces empathic feelings from the chaplains.

\section{"Treating him like dirt"}

Participants speak with emotion, they are angry at the treatment and conditions that seafarers must endure, and frustrated by the ignorance of the Western world and their demand for goods.

Who really cares about all those people dying? I'm alright. l've got my 95\% sitting in my comfort zone, so I'm not really going to queer the pitch, all the time somebody's bringing it to me why should I worry? (Peter)

All 6 of the participants had strong feelings of admiration and respect towards seafarers, working for the good of the Western world for little reward. The necessity for seafarers to provide for their families leaves seafarers with no choice but to endure the harsh reality of life on a ship. The world of seafaring is tough and relentless, but seafarers return to sea again and again. Chaplains recognise the necessity for seafarers to endure conditions because of family and financial commitments.

There is convergence amongst all 6 participants of the injustice of the treatment of seafarers for the benefit of the West. The anger and frustration is evident from their accounts and their use of vocabulary; "no concept", "dirt", "struggle", "their lives at risk", "wrong", "dignity", "semislave". Participants speak with anger and frustration at the injustice, and infringement of human rights. Perhaps, their sense of anger and frustration is in part due to they themselves being a part of the Western world they are condemning. Given the sense of injustice, participants allude to a crisis of identity, on the one hand they are providing support for seafarers, paradoxically, they are part of the Western society placing the demands on seafarers and perpetuating the market demands. This anomaly evokes feelings of empathy from participants, which generates the next sub-theme. 
"I do not blame anybody who doesn't want to go ashore"

The immorality and harsh treatment of seafarers brings with it concomitant feelings of empathy from all participants, as well as the strong feelings of admiration and respect. Dealing with the emotion and distress of seafarers is a frequent occurrence for chaplains. Matthew says:

Sometimes they just want to express their upset and say, “Look, I'm hurting", and you say, "Yes, I know". (Matthew)

Chaplains cannot imagine themselves in the same position and feel a degree of empathy and sympathy for those at sea;

Since the emotional, mental, spiritual state of person does affect the healing process it is important to show er...maybe a bit of pity and care for that other human being. (James)

The first superordinate theme, illustrated participants strong sense of identity. Their unique role, facilitated by the historical relationship between the church and the maritime world, further solidified by the personal impact they felt they have by "listening" and "being there". The second superordinate theme, alluded to a crisis in that identity. There is a strong sense of injustice, followed by feelings of empathy, for the mistreatment of seafarers by the developed world. This induced strong emotions from participants, and acknowledgement that themselves, as members of Western society, are perpetuating the living conditions of the seafarers they support.

How do chaplains cope with this incongruence? How do they resolve this conflict of identity? This brings us onto the final superordinate theme.

\section{3. "PATCHING UP"}

The import/export industry sees quick turnaround times for ships, meaning that all too soon, they are heading for the next continent, the next country, the next port and the next chaplain. Participants are aware that their contact with seafarers is fleeting and the pressure to assist, help, listen and support is felt by all. This super-ordinate theme encompasses the limitations that chaplains feel, the adjustments they make, and how they cope.

\section{"I am only a guest"}

Participants report feeling limited in what they are able to achieve and how much support they are able to provide for seafarers. Practical logistics of a busy port, means that time is at a premium. For vessels with a quick turnaround time, chaplains no longer wait for seafarers to visit the seafarer centre, but board the ship to offer support and welfare. The limitations are not just about time constraints but in their lack of authority to make any change. James feels this quite strongly and this is difficult for him;

I am only a guest and hold no powers in my own right. (James)
There is convergence amongst participants, that as a result of restrictions of what they can do, small acts of kindness come to represent a more symbolic gesture of care and support.

To show them another human being who cares, is not using you, cos when you look closely, we don't provide much, it's only a data card or a bit of wool turned into a hat. (William)

The woolly hats provided by members of the public in and around London, are a good example of how the small act of kindness becomes a symbolic gesture of care. Some gestures are bigger than others, the priority for all seafarers is contact with loved ones and often, providing the means for which a person can contact home is more than a symbolic gesture, but a vital need to anyone away from home for long periods of time.

I got a chap a SIM card last week and I got hugged. He was so happy he hugged me... you know, we can go to the shops and get one, but to him it meant he could contact home, and I think for me that's the best bit, just being able to help with peoples' vital needs. (Matthew)

Feeling valued and helpful when there are such limitations, becomes a coping strategy for the chaplains. It appears that chaplains overcome practical limitations by achieving goals (irrespective of how small) that boosted seafarers' self-esteem and self-worth. Achieving these goals reduced the dissonance between what they can do and what they wish they could do.

\section{"Christ offered salvation, and not an easy life"}

Participants' accounts of their experience are accepting of the limitations imposed on them and the level of support and welfare they are able to offer.

A long as the person, when they come into my little area of control, leave my area of control, feeling cared for, thought about and happy, then I have done my job and they can survive the next couple of months. I hope my other colleagues in the other places are doing exactly the same, this is the way this little group or family will be looked after. (Peter)

Peter speaks with great affection when he talks about seafarers, though he is accepting that he is only able to provide support and welfare for the period of time seafarers are in his "area of control". He places the responsibility with the ship owners;

They will force you to put up with it until the International community says we are not prepared to tolerate the abuse of our family. There's nothing you can actually do, I think, but actually listen to him and I think that's what you do, listen to him. (Peter)

Matthew, as a younger chaplain, seems to find acceptance harder than the others, though maybe this is a result of his age and inexperience, and speaks with reluctance when accepting the limitations; 
You can see there is an injustice, you can see a seafarer has been wronged but you can't do anything about it because it's not within your remit. It's not your job and sometimes you just plainly can't do anything about it. (Matthew) The process of acceptance is facilitated by the potential consequences of acting on an injustice;

There are situations where I can only say to a seafarer, "Yes your treatment is not fair, it is not good for you, but the possible implications if we do something are so grave that I wouldn't do anything. I would endure the situation", that then, can be challenging. (James)

This dichotomy between acceptance of a situation and the injustice of that situation is something that causes conflict for James;

Where you stabilise the situation and make it possible to continue, whereas you would prefer to sort of end it, it's part of the conflict that a minister is continuously in. (James)

James accepts that any support and welfare he is able to provide is only temporary. He is unable to eradicate problems, and therefore strives to assist seafarers in adopting an effective coping style, he is "patching someone up" and "the glue" that is;

...trying to strengthen their resilience, the ability to cope with the situation by themselves because you are not going to be there. (James)

Though James attempts to provide seafarers with the skills to cope, and speaks of "resilience" and "strength" he in part, uses a reference to God to encapsulate his feelings of both constraint and acceptance:

Christ offered salvation, and not an easy life. (James)

Given the crisis in identity outlined earlier, and the associated emotions of injustice and empathy, "acceptance" was a fundamental component in participants' adjustment to making sense of providing welfare to seafarers. The process of acceptance was facilitated by the knowledge that participants had no control over seafarers living conditions, and that by providing a "listening ear", they were doing as much as they could to "patch-up" seafarers until their next port. In this way, acceptance may represent a coping strategy aimed at providing the experience of positive emotions [13].

This superordinate theme has also illustrated, that in addition to acceptance, adjustment to the reality of constraints placed upon chaplains took the shape of realistic goal setting. Small symbolic gestures, re-introduced a sense of personal control and of "providing welfare", be it a SIM card or a lift to the supermarket. This gave participants their self-worth and placated feelings of "helplessness". Acceptance and adjustment therefore contributed to participants' coping style and shall be discussed in the next section with reference to psychological theories.

\section{DISCUSSION}

The current psychological literature neglects the experience of chaplains despite their close proximity with patient groups, people in distress and those that have experienced trauma. This analysis has shown that the way chaplains make sense of their experiences in providing welfare for seafarers is complex. In this section, analytic observations already made will be expanded and discussed in relation to current psychological literature. Firstly, the role of self-efficacy theory $[14,15]$ and its influence on the personal impact of chaplains, facilitated by the historical role of the Church and the identity that comes with being a chaplain. Secondly, the theory of empathic responding [16] will be examined and how this can be broken down into sympathy and personal distress. Lastly, a look at how chaplains adapt, accept and cope with providing welfare to seafarers, often dealing with trauma and chronic stress, using the Transactional Model of Stress and Coping [17].

Self-efficacy beliefs are judgements about how effectively a person believes he or she can act in order to meet a goal or to effectively cope with challenging situations [14]. Theories of self-efficacy state that it influences self-regulation and the amount of effort people invest in a given task. This is a relevant construct for participants in this study and is evident from the personal impact they report having. They all spoke with confidence and conviction and they felt their role was valuable and essential.

Self-efficacy is further facilitated by the historical role of the Church and the long-standing history of the maritime world and missions. Port chaplains are well established in their role and position, as a person who provides pastoral, impartial welfare. Seafarers are aware of who they are, and what they can offer before they even anchor in a port [18].

This perceived self-efficacy, contributes towards the psychological effectiveness and psychosocial adjustment-styles of individuals in relation to their particular environments [15]. Empirical research of adaption of well-being, illustrates that those who believe they can deal effectively with stressors are better at dealing with stress and adopt more effective coping styles [19]. Participants in this study report high levels of self-efficacy, they are confident in their ability and believe they make a big impact on the welfare and well-being of seafarers.

In addition to high self-efficacy, participants demonstrated high levels of empathic responding, an important predictor of interpersonal functioning, and helps to nurture understanding and caring in relationships, which helps both the chaplain and the seafarer in relation to emotion-focused coping [16]. Definitions of empathy have varied over the years, from emotional to cognitive. There is some convergence between definitions in recent years, that empathy requires some awareness of distinction between one's own 
emotions and another's [20]. Accounts of participants in this study fit well with the theory of Empathic Responding, as they express strong feelings of empathy for seafarers. Eisenberg [16] hypothesised that the empathic responding theory, could further be broken down into two components; sympathy and personal distress, and highlights the distinction between one's own emotions and another's.

"Sympathy" is evident in participants' descriptions of seafarers' working conditions, long hours, lack of communication with home, feelings of fear when faced with unpredictable voyages or destinations. Participants recognise that since most seafarers are from developing nations, and therefore feel obliged to suffer the conditions and confinements of being at sea. They do not feel in a position to complain or speak out, since they risk losing their job and have family to support. This fulfils the criteria for the first component of Eisenberg's theory (sympathy). Secondly, the working conditions of seafarers' evokes feelings of injustice, of seafarers being "wronged", and this causes personal distress to the chaplains, presenting as anger and frustration, highlighting the second component of Eisenberg's theory of empathic responding (personal distress).

Theoretical underpinnings to interpret participants' accounts have examined both self-efficacy and empathic responding theories. Finally, the Transactional Model of Stress and Coping [17], describes the interaction between a person and the stress from their environment. A person uses the Theory of Cognitive Appraisal [13] to assess the situation, that is, they consider the threatening tendency of the stress and the resources present to minimise or eradicate the stress. They are then faced with two approaches to coping. These are problem-focused coping and emotion-focused coping. Problem-focused coping is used when we feel we have control of the situation and can manage the source of the problem. In a situation where we have no control a person adopts an emotion-focused approach, such is the case of the participants in this study.

Chaplains adopt a coping style illustrative of emotion-focused coping themselves and also allude to it when they are supporting seafarers. "Listening" and "being there" are stated by participants as the prime value that they give, the aim being to reduce negative emotional responses, the key component of emotion-focused coping [13].

Adaption is a key element to emotion-focused coping, and is demonstrated by the adjustment chaplains make in the significance they place on the small gestures they make. Chaplains are aware of the limitations on them to assist and there is a limit to what they can do to help. Practical errands such as driving seafarers to the supermarket to stock up on vitamin tablets, powdered milk and presents for their children are among the most popular requests. Small gestures such as these, become significant symbols to the seafarers that someone cares. The most significant errand chaplains perform is to supply seafarers with SIM cards so they can contact home. Participants are aware of the impact this has on the seafarers' well-being and welfare, and make every effort to help seafarers in any way they can and is a rewarding part of their role. Since problem-focused coping is not possible for the chaplains, they cannot improve the situation for seafarers nor can they influence ship owners. They adapt, and the small gestures and errands take on a new significance.

Chaplains adopt an emotion-focused coping style, in part because a problem-focused coping style is out of the question and secondly, they act alone in their role, with no support from other healthcare professionals in the NHS or otherwise. They provide counselling support for people in distress and after experiencing trauma, where their only support is from the team of chaplains that they work within. Suggestions for future research include looking at the role new or existing healthcare services should play in the psychological well-being of seafarers visiting our shores, and thereby providing support for chaplains on the frontline of care.

\section{CONCLUSIONS}

This study has provided some insights into the experience of port chaplains. By selecting an IPA approach, this study has made a much-needed contribution to the literature concerned with the personal accounts of chaplains and how they make sense of providing welfare to seafarers. While it is acknowledged that broad generalisations cannot be made, this research has provided rich, qualitative data from a previously neglected group. These findings may provide suggestions of clinical implications and a need for involvement from new or existing healthcare services. Recommendations are made for a biopsychosocial model of health involving primary care, benefiting the health and well-being of seafarers and providing support and guidance for port chaplains at the frontline of welfare for seafarers.

\section{REFERENCES}

1. Roberts SE. Britain's most hazardous occupation: Commercial fishing. Accident Analysis \& Prevention 2010; 42: 44-49. doi: 10.1016/j.aap.2009.06.031.

2. Baker M. Sea chaplains: serving their country with pride. Headmark 2014; 151: 74-79.

3. Winter-Pfändler U, Flannelly KJ. Patients' expectations of healthcare chaplaincy: a cross-sectional study in the German part of Switzerland. J Religion Health 2013; 52: 159-68. doi 10.1007/ s10943-010-9451-7.

4. Smith JA. Evaluation of the contribution of interpretative phenomenological analysis. Health Psychology Rev 2010; 5: 9-27. doi: 10.1080/17437199.2010.510659.

5. Shaw RL. The future's bright: celebrating its achievements and preparing for the challenges ahead in IPA research. Health Psychology Rev 2011; 5: 28-33. doi: 10.1080/17437199.2010.524808. 
6. Brocki JM, Wearden AJ. A critical evaluation of the use of interpretative phenomenological analysis (IPA) in health psychology. Psychology Health 2006; 21: 87-108. doi: 10.1080/14768320500230185.

7. Elkin G. Industrial Chaplains. Employee Counselling Today 1992;4:17-25.

8. Dickson A, Knussen C, Flowers P. "That was my old life; it's almost like a past-life now": identity crisis, loss and adjustment amongst people living with Chronic Fatigue Syndrome. Psychology Health 2007; 23: 459-476. doi: 10.1080/08870440701757393.

9. Eatough V, Smith JA. I feel like a scrambled egg in my head: An idiographic case study of meaning making and anger using interpretative phenomenological analysis. Psychology Psychotherapy Theory Research Practice 2006; 79: 115-135. doi: 10.1348/147608305X41100.

10. Smith JA. Qualitative psychology: a practical guide to research methods. UK. Sage, London 2006.

11. Jarman M, Smith JA, Walsh S. The psychological battle for control: a qualitative study of health-care professionals' understandings of the treatment of anorexia nervosa. J Comm Applied Social Psychol 1997; 7: 137-152.

12. Kverndal R. The way of the sea: the changing shape of mission in the seafaring world. William Carey Library Publishers, California 2013.

13. Lazarus R, FolkmanS. Stress, appraisal and coping. Springer, New York 1984.
14. Di Giunta L, Eisenberg N, Kupfer A, Steca P, Tramontano C, Caprara GV. Assessing perceived empathic and social self-efficacy across countries. Eur J Psychological Assess 2010; 26: 77-86. doi: 10.1027/1015-5759/a000012

15. Bandura A. Evolution of social cognitive theory. In: Smith KG, Hitt MA (eds.). Great minds in management. Oxford University Press, Oxford 2005; pp. 9-35.

16. Eisenberg N, Eggum ND, Di Giunta L. Empathy-related responding: associations with prosocial behavior, aggression, and intergroup relations. Social Issues and Policy Review 2010; 4: 143-180. doi: 10.1111/j.1751-2409.2010.01020.x.

17. Lazarus RS, Cohen JB. Environmental stress. In: Altman I, Wohlwill JF (eds.). Human behavior and environment. Vol. 2. Plenum, New York 1977.

18. D'Amico S, Marano A, Geraci MA, Legge E. Perceived self-efficacy and coping styles related to stressful critical life events. PLOS ONE 2013 8: ).

19. Holden G. The relationship of self-efficacy appraisals to subsequent health related outcomes: a meta- analysis. Social Work in Health Care 1991; 16: 53-93.

20. Decety J, Ickes W. The social neuroscience of empathy. MIT Press 2011. 